\title{
Political state and the dilemma of dignity, equality and freedom: Evidence from a sovereign state
}

\author{
Md. Mahfuzur Rahman Khan
}

Institute of Social Welfare and Research, University of Dhaka, Dhaka, Bangladesh

mahfuzur.rkm@gmail.com

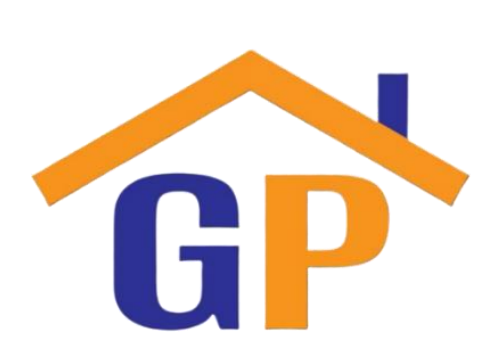

\begin{abstract}
Purpose: This study discusses the idea of political redefinition and its connection to dignity, freedom and equality in a sovereign state. This article concludes by briefly touching on some serious issues about sovereign communities that arise as a result of the fundamental dignity, freedom, and equality ideals of the sovereign state.
\end{abstract}

Research methodology: The author decided to conduct theoretical research in a qualitative format using conceptual analysis as well as critical and rational argumentation. A deductive approach is used in

Article History

Received on 12 July 2021

Revised on 5 August 2021

Accepted on 5 August 2021 reaching a prior opinion.

Results: The sovereign state itself became the judge and restricted human dignity, equality and the freedom to contract by forcing citizens to make transfers they did not consent to and prohibiting certain private transactions on the sole pretext.

Limitations: There are shortcomings in theoretical research, as the author used a deductive approach to conclude.

Contribution: This study conceptualizes the proponents of a sovereign state to be drawn into the dilemma of dignity, freedom and equality.

Keywords: Political redefinition, Political stability in a sovereign state, Dignity, Freedom, Equality

How to cite: Khan, M. R. (2021). Political state and the dilemma of dignity, equality and freedom: Evidence from a sovereign state. Dynamics of Politics and Democracy, 1(1), 29-37.

\section{Introduction}

Human dignity, freedom, and equality appear to be things that practically all individuals desire on a fundamental level. It is a foundational articulation of the life experiences that have gained authority as a result of the convergence of demands from people all over the world. Despite this, the concept of human dignity, freedom, and equality is in a state of chaos that is counterproductive. "How citizens of different nations perceive themselves as members of their political community is determined by the different weightings citizens of different nations assign to either rights and liberties, or inclusion and equality, or deliberation and problem solving," according to Habermas (2006). Respect for one's dignity, freedom, and equality can be seen as a precedent, a result, a value, a guideline, and an experience from a variety of viewpoints, including intellectual, constitutional, pragmatic, psychological, behavioral, and cultural.

This political redefinition and the establishment of new norms have not, moreover, prevented, like the changes in rhetoric that have resulted from it, that the difference between the gender remains the starting point and the point of reference of a great number of political distinctions. The resulting consequences have been and still are referred to as political inequalities, but also as situations of oppression and domination. The political state constrained, contrary to the dogma that everyone should own their person and the product of their efforts, those best equipped to transfer part of their wealth to the poorest, that this is in the form of public services financed by a progressive tax or in the form of transfers and 
allowances of any kind. However, the dogma of classical liberalism required on the contrary that the charges be equally distributed among all the citizens in proportion to their contributory faculties, which implied that it is forever forbidden to take what belongs to $\mathrm{A}$ and give it to $\mathrm{B}$.

The study discusses the concept of democracy and its relation to the principles of dignity, freedom and equality in a sovereign state. The fundamental ideas governing the principles of dignity, freedom and equality are offered. This essay finishes by commenting briefly on several problematic concerns concerning sovereign communities because of the sovereign state's core dignity, freedom and equality values.

\section{Theoretical framework \& literature review}

Building dignity as a highly subjective experience has certain problems. How does dignity affect societal and political processes, where dignity is an objective statement linked to the acquisition of specific desired values? What determines the optimum level of realised values related to the person's experience of dignity, perhaps even in principle? The moral freedom of the person is the original freedom of self-disposition by rational choice, which is defensible against the entire world and all others (O'Donovan, 2010). Equality involves justice and fairness that needs not only that people are not discriminated against unfairly but that freedoms are also distributed evenly through fair equal opportunities (Rawls, 1999).

Human dignity is not an individual but a normative status, which is conferred on every person regardless of origin, capacity, success, gender or ethnicity. It does this in a way that human people are so tied together rather than divided from one another (Vogel, 2007). Currently, the concept of human dignity is in such disarray that it cannot even serve as a minimally stable framework for international discourse and action (Freeman, 1994; Ashcroft, 2005; Caulfield and Chapman, 2005). Much of this concept remains implicit or even contradictory, serving a variety of different and sometimes antagonistic ends in the service of dignity (Macklin, 2003). Those who use the free expression of their opinions to harm the honor or pride of others are shooting with words (Esterhuyse, 2004). As Merrill (2004) points out, press freedom almost always results in the adoption of best journalism practices. To ensure that the news is covered to the greatest extent possible, freedom is required. According to this interpretation, the principle of freedom is operationalized as doing what you want without considering the other person. Because of this liberty, there is an atmosphere of unhappiness, where "communities live in fear, hidden behind walls and barbed wire, ever anxious in their homes, on the streets, and on our roads, unable freely to enjoy our public spaces" (Mbeki 2004). The feminist movements have put forward, in general, and in many details, the facts, themes and issues associated with them, they have politicized them and have emphasized what is unacceptable, while seeking to subject them to theoretical analysis and to study them from the point of view of political theory, from different perspectives, in particular those of feminism. Simultaneously, both the development and the implications of the development of femininity and masculinity and the structural and symbolic arrangements for gender in a particular society have more probability to label the work as male or female (Khan, 2021), in case of dilemma in dignity, equality and freedom. Since the right to respect is inviolable and not left to arbitrary decisions of others, it is the State's duty to respect and preserve such rights where they are challenged (Vogel, 2007).

\section{Methodology of the study}

The majority of this study is theoretical in nature. The study has been conducted using qualitative means, as "qualitative research intends to examine and discover issues about the issue available because there is little consideration given to the issue in quantitative research" (Khan, 2020a) thus it is necessary to use conceptual analysis as well as critical and rational argumentation to conduct the study. Through the use of conceptual analysis, an investigation is carried out into the application of certain concepts in specific, or in all possible, contexts. Conceptual analysis is particularly suitable if there is confusion or concepts can arise. The conceptual nature of the study is acknowledged because, as De Vos et al. (2005) points out, "a conceptual analysis is potentially infinite - there are always more research areas to be followed." Although the argumentation offered by the following paragraphs is limited by conceptual analysis, they try to produce indicators that hopefully stimulate further research. A deductive approach is used in reaching a prior opinion (Khan, 2020b), by conducting several arguments. 


\section{Dignity, equality and freedom: The dilemma}

The decent society was undoubtedly born from this pragmatism of a part of the elites, little by little converted to the questioning of an understanding of individual freedom which reduced it to equal rights and which affirmed that political inequalities were the natural and necessary consequence of the latter. In this sense, individualist societies have come to think that they could not stabilize their institutions and resolve the legitimacy problems they encountered due to the exclusion of the working classes without trying to guarantee their members, not the right to do so. to be subject to equal rules but a right to a certain share of the wealth produced by the collectivity, or at least to a share of this wealth as large as possible without significantly affecting the total mass to be distributed and share. This feeling acquired a force all the greater as the increasing division of labour and the interdependence of activities made illusory the idea that the part which belongs to each according to the laws of the market alone represents the exact reward of his contribution. The "political" state, first of all, required that people abandon the idea that equality before the law is the necessary and sufficient condition for the freedom of individuals. It supposed, contrary to the principle of impartiality, an active intervention by the public authorities to strengthen the position of the weakest and limit, utilizing new rights (political or "positive" rights to health, education, housing, etc.), the pressures that increasingly concentrated property could put them under. But these new rights have a paradoxical aspect from the point of view of classical liberalism, which is that they cannot in any credible sense be "identical for all" and that they necessarily imply that individuals are treated unequally in a way that is depending on their situation.

Pipes (1999) states: "The symbiotic connection between property and freedom does not prevent a country from placing appropriate restrictions on the use of property, or from guaranteeing the fundamental living conditions of the population's most needy stratum. One cannot allow the rights of ownership to act as a license to damage the environment or ignore the basic needs of the unemployed, the sick and the elderly."

The law, therefore, changes the distribution of burdens: where previously they were entirely the responsibility of the employee, treated in this respect like any citizen contracting with another, they now fall partly on the employer and partly on the employer. the community as a whole which pays, with the products it buys, a share of the cost of safety devices, as well as the costs of accidents that continue to occur. It is easy to understand that the previous legal equality - everyone, whatever their situation, bears the consequences of their actions - resulted in inequality so glaring that it was only right to correct it. Detailed studies had, moreover, established that more than four-fifths of accidents occurred during the last two hours of the employee's working day and that, therefore, political conditions were more to blame than individual responsibility. But the law is no longer the same for everyone. People have thus moved from a premise of state action to the idea of a mission (of a compulsory nature). For an essential part, namely in its political form, belonging to a genre thereby loses its appearance of pre-political and almost "natural" evidence to become a politically contingent phenomenon, on which people can act and which implies responsibilities. Historically, this change jointly affects other political distinctions conceived as traditional, which are publicly questioned as such.

\section{Dilemma of dignity, equality and freedom: Arguments}

According to many who are concerned with the promotion of human dignity, equality and freedom, the conferring of dignity, equality and freedom by governments or people on others seems to be more of a desired result or effect than a helpful diagnostic or a foundation for wide consensus. A value-based subjective conceptualization of human dignity, equality and freedom, framed about the commonwealth, potentially fulfils the standard of sufficiency. This notion allows for the diverse ways that individuals experience dignity, equality and freedom in different contexts as a subjective phenomenon, but contingent on social interactions and the experience of dignity, equality and freedom by others as a commonwealth. As such, a value-based conception offers a potentially stable global frame that invokes broad-spectrum functional values, including values related to duties and physical well-being. Such a concept explicitly links to human rights, human social psychology (e.g., subjective well-being), and non-Western perspectives that include attaching greater weight to duties and obligations and less to individual entitlements and freedoms. And yet this conceptualization potentially yields standards that 
transcend specific contexts. It is hard to imagine any group of people experiencing a commonwealth of human dignity, equality and freedom when they have been excluded from participation in creating dignity, equality and freedom-relevant policies and practices, experienced widespread degradation and been chronically deprived of necessities such as shelter, food, and healthcare. This view, on the other hand, makes no explicit or diagnostic statements regarding the aspects of other people's dignity, equality and freedom. As a social analyst, one may consider the psychological and social dynamics of granting dignity, equality and freedom to others to be essential considerations for consideration. Not being able to define how these bestowals were constructed, or what activities constituted dignity, equality and freedom-granting as opposed to dignity, equality and freedom-depriving actions from the standpoint of self, much alone from the perspective of others is a major limitation.

These are multi-layered political developments, complex phenomena and situations. For some time now, they have been the subject of lively debates and controversies in which heterogeneous points of view clash, as much in the field of daily life as in the framework of political movements, in the scientific field as in the field of science. political policy framework in the strict sense. Thus, within the framework of research on gender, some affirm that the principle of inequality of the sexes found in nature, with the consequences which ensue from it, and the political assignments of the same type tend to lose their substance, their legitimacy. and hence their importance in the course of political changes; others dispute this thesis, pointing out that these are only superficial changes. The proponents of the first position, for example, advance the argument that the model of gender equality, by establishing itself politically as a norm, promotes the perception of gender inequalities as an "injustice". Consequently, the author considers it "surprising" that the thesis affirming the perpetuation of specific gender inequalities is still so widespread in sociology; for them, the question is rather to know why this topic is still politically on the agenda. The antagonistic positions that have evoked here, in detail, only by way of illustration and in a schematic fashion, have a history and are linked, in a systematic way, to a larger framework of discussion.

These arguments are not without weight. The welfare state indeed faces problems of efficiency. It is also true that the concept of freedom on which it is based - equal access to the means of independence implies a problematic rejection of the principle of impartiality and the equally problematic transformation of the legal universe into a tool of political equalization. But they are not enough to cancel the intuitions which gave birth to the political state and presided over the development of decent society: inequality affects the substance of freedom because, in a society of individuals who aspire to be autonomous and to live apart from each other, there is no other possible source of legitimacy than, precisely, this guarantee of equal access to the means of independence. Guaranteeing the identity of rights and the impersonality of rules is no longer sufficient when, under the impact of the inequalities to which they have given rise, the results become easily predictable. The founders of liberalism themselves insisted that the legitimacy of the society of individuals rested on the universal character of the promise of liberation, on the recognition of the equal moral worth of all. They underlined that if aristocratic societies imposed intolerable legal obstacles - privileges - on the personal aspirations of individuals, they would no longer have to overcome, in the new society, other limits than those of their lack of capacity or their lack of energy. It is, however, less than certain that the societies really born of democratic revolutions corresponded to this image and that equality of opportunity prevailed there.

\section{Sovereignty of a political state: Arguments}

A sovereign country is a political body represented by a centralized state, which has sovereignty over a geographical area and according to international law, sovereign states are those that have a permanent population, a defined territory, a single government, and the ability to engage in diplomatic relations with other countries (Nathan, 2003). In political theory, sovereignty refers to the supreme overseer, or jurisdiction, in the judicial procedure of the state as well as in the preservation of order in a given society. The notion of sovereignty, which is one of the most contentious conceptions in politics and international law, is intimately linked to the problematic concepts of state and government, as well as the concepts of independence and democracy, among other concepts of difficulty. The economy began to stagnate, entire groups created situational rents sheltered from the protective State, the public nature of the expenditure generated a certain irrationality, the feeling of responsibility of individuals grew. is 
blunted under the impact of increased protection. The state itself has fallen prey to lobbies and special interests, the least powerful of which is arguably not the huge army of officials who have proliferated in the shelter of their new functions.

All these evils were known and denounced even before the creation of the political state. Before they could even see it with their own eyes, the classical liberals had announced that, in a democratic regime, a redistributive state risked becoming a tool of predation of the rich in the hands of the greatest number and that, in reaction, the money powers would seek in their turn to corrupt the political personnel and to enlist them in the service of their interests to give birth to what they called the plutocracy. They also sensed that, under a legal regime that authorizes the legislator to manipulate the right to property to disseminate its benefits and to frame the right to contract to limit the pressures it authorizes, the very notion of individual liberty could be affected. very damaging erosion.

The political state was born from a reflection of this kind. It is therefore based - at least implicitly - on the idea that the impartiality of the law and the uniform guarantee of rights protecting increasingly asymmetric powers of constraint cannot constitute the unsurpassable language of individual freedom because of the inequalities of increasingly important - and the legitimacy problems that they generate to which its undivided application leads. Better yet, it is based on the idea that the equal guarantee given to unequal material powers is the strict analogue of legal privilege. In other words, he postulates that equality before the law may well be an outright myth because a law that also protects unequal properties can in no way be called equal.

\section{Freedom \& other rights in a sovereign state}

Freedom, after all, cannot be insured against the risk of losing out in a fair competition. It is only the assurance of being able to take part without a handicap. It is therefore important not to confuse the two forms of guarantee: being able to pursue a goal without unnecessary hindrance and having the assurance of reaching it. The political institutions can grant the first, but they cannot promise the second to all without an illusion fraught with all the dangers because, to guarantee to each one the bases of effective freedom or a real frankness, they are forced to do very serious breaches of equality before the law, to break with the principle of self-ownership and to organize a redistribution that makes public power what, in the eyes of classical liberals, it should never be: a body that works alongside some. The dogmas thus implicitly called into question by the reality of the welfare state were, however, until the beginning of the twentieth century, the dominant or "classic" version of liberalism: impartiality of laws, refusal of privileges, the guarantee of equal rights, protection of property and the right to contract, reduction of the role of public authorities in the prevention of coercion and fraud. It is, however, indisputable that these dogmas left a question unanswered: the founders of this vast intellectual and political movement of rupture with the hierarchical and aristocratic societies of the old regime which we call "modern liberalism" conceived these ideas as an end in itself or as a means of promoting the independence and autonomy of all individuals? Were they convinced that, whatever the material and political context, they are the very form of free institutions, or did they conceive of these legal tools as means of maximizing the "frankness" of individuals by allowing them to dissolve privileges? legal and create political conditions in which everyone could appropriate through their work the bases of their independence? Are equal rights the ultimate formula for individual freedom, or is it just a way to remove the barriers to real independence that are the legal privileges of the old regime? If the second hypothesis is correct - that is, if the primary justification for liberal principles is "consequentialist" and not "deontological" in nature - supporters of individual freedom are undoubtedly entitled to question the institutional and legal conditions of the latter when they see that the market, the impartial law, and the impersonality of the laws guaranteeing the property and the contract lead to the concentration of wealth, to new forms of dependence, and to the reconstitution "feudalities" which are no longer those of birth but those of money. If the legal framework of the impartiality of the law derives its legitimacy only from its capacity to promote or make effective the access of the greatest number to effective independence, it should be bent or modified when it ceases to generate the consequences for which it was instituted. The idiom of classical liberalism therefore no longer seems adequate when the conditions in which it is spoken and implemented - an increasing asymmetry of positions under the very effect of the impartiality of the rules - cause it to generate dependence on instead of reducing it, and that it 
destroys the bases of autonomy instead of guaranteeing them. It was suitable when the essential obstacle to the real independence of all was the asymmetry of rights, but it is by no means obvious that it remains so when this essential obstacle is no longer the asymmetry of rights but, on the contrary, the asymmetry of powers that arises in the context of equal rights. An unpopular opinion by an employee of a privateowned company stated below,

“.........first has a right to use that thing to meet his needs, and this right increases his freedom, as he increases his ability to resist pressures and personal constraints that others might impose on him if he had to turn to them for what he needed. If his property rights are sufficiently extended, he can, for example, refuse to take up a job he dislikes or accept a very low salary. But in addition to the right to use what he owns, the owner also has the right to negotiate what belongs to him and to sell it on the market, therefore to obtain an income which, in turn, gives him access to consumer goods. The property right, therefore, confers on him, in the second place, freedom to resist the impersonal forces of the market and to remove the obstacles which intervene, because of the property rights of third parties, between his needs or desires and things, that belong to others."

Such analysis proves that the freedoms acquired by property and guaranteed by the law which protects it varies according to the size and nature of the property itself. The freedoms conferred by owning an old hat - this is Hale's example - are not the same as those would be guaranteed by owning an oil well. It is equally clear that the restrictions and constraints - the actions which are made impossible for us introduced by the right to property are not at all the same according to the individuals. To realize this, it suffices to compare the respective effects of two prohibitions: on the one hand, the prohibition against attacking others, for example hitting them in the face; and on the other hand, the ban on interfering with what belongs to others. In the case of the prohibition against assaulting others, the statement of this prohibition and the concomitant right of others not to be assaulted is sufficient to define which actions are prohibited (or which actions against which we are guaranteed), and these actions are the same for everyone. Another way of expressing this idea is to say that the mere outward description of a person's conduct can tell whether or not they have assaulted a third party. But the same is not true of the prohibition against interfering in what belongs to others and in the concomitant right of ownership of each person over his property. In this second case, the list of permitted and prohibited actions will vary according to the individual and no physical description of any action will allow saying that the one who engages in it violates the property right; to reach such a conclusion, it is indeed necessary to introduce an additional proposition affirming that the object which he has seized belongs to others. The right not to be hit in the face is, therefore, an equal right because everyone has a face; but the right not to interfere within the use and market disposition of what one has is not equal because not everyone has the same thing. The system of rights and constraints that results from the institution of a right of ownership over different and unequal things is specific for everyone, while the guarantees and constraints resulting from the right not to be attacked are the same for everyone. the world. Of course, the owner of the old hat has the same power to prevent others from interfering with what belongs to him as the owner of the oil well, but no one would seriously think of saying that these two rights are equivalent; the best proof is that any offer to trade them for each other - or to regard them in any way as interchangeable - would sound like a bad joke. This has important consequences. For classical dogma, the equal protection of the laws was the exclusive form of the impartiality constitutive of individual liberty, and this is the reason why, according to this dogma, any rule which would grant unequal protection (i.e. which would favour certain members of society at the expense of others by granting them income, rights or additional capacities to resist pressure) would be destructive of freedom.

\section{Equality in a political state: Question to sovereignty}

Equality is the condition of things in which all persons in a given society enjoy similar rights, freedoms and status, including potential civil law, freedom of speech, autonomy and fair opportunities to certain public social goods and services. Social equality implies the lack of legally imposed social or caste barriers and the elimination of discrimination based on an inalienable element of the identity of a person. Conversely, if two people are unequal, treating them unequally, for example conferring certain advantages or rights on one but not on the other, could have the consequence of making them more equal (or less unequal than they are). were previously). Even though the redistribution of resources 
could have the effect of contracting overall wealth and therefore harming those it claims to favour, the transfer of resources is not in itself a destructive bias of equality since 'it too could have the effect of making two people more equal than they were previously. The idea that, in all circumstances, legal equality is the ultimate form of equality is therefore no longer consistent. And if the freedom of the individual lies in the fact of being treated as having equal value, which implies respect for his moral independence and the absence of any subjugation to others or any form of control of a will foreign on the essential conditions of its existence, such freedom could be increased thanks to the rupture with legal equality or with an impartiality which, by protecting unequal powers, subjects individuals to pressures and "attributes" to them the capacities of the act that are very different from each other. Here too, "unequal" treatment could re-establish greater equality by attributing new resistance capacities to those who have the least and by preventing those who have the most important assets from making certain uses of them (for example through a limitation of the right of ownership or taxation of certain forms of the transaction). Equality of law, therefore, does indeed lead to real freedom (the independence of each person) in a context where the powers of constraint and access to the means of work are similar or relatively similar. But it ceases to guarantee this reciprocal independence when this contextual condition is no longer fulfilled. The only justification for equal rights was to guarantee individuals against the forms of asymmetry that inevitably resulted from the existence of legal privileges. If it is no longer sufficient to ensure this guarantee of effective independence, it must be reshaped in the name precisely - of this primary egalitarian requirement: no one should live in conditions such that their conditions of existence are controlled by others. If resource transfers and differentiated rights are necessary to preserve this effective independence, they are therefore legitimate. By protecting the property right, protects unequal powers and capacities, it is quite possible, on the contrary, that a "partial" law introduces a greater and more real equality than that which existed before. In other words, the injunction that the law should be the same for all does not make sense if all are not equal, and the idea that equal protection of unequal powers may be the definition of equality is absurd.

This argument comes up against an insurmountable difficulty, which is the practical impossibility of drawing an unambiguous and objective border between actions that only affect the one who carries them out and those which affect others. Any reasoning which attempts to determine the respective holders of collective control and individual liberty is therefore obliged to introduce a conception of what an independent life means, a properly human existence, and to draw conclusions about them. actions that must be left free because they are compatible with the independence of all and those which, on the contrary, come into conflict with this requirement. However, within the framework of reasoning of this kind, it becomes difficult to claim that economic pressure is not a constraint and that the community does not have the right to try to control its effects as it tries to. curb those of the most direct constraints.

\section{Findings on the arguments}

The partisans of an alternative conception of freedom should therefore not be impressed by the kind of right of preemption that the followers of classical liberalism claim to exercise over this concept when they argue that, outside the impersonality of the rules, individual freedom disappears due to the state's commitment to maintain or improve the situation of the less favoured political groups. While it is true that they are required to speak a political language that differs from that of equal rights because it underlines the impasses of a conception of freedom which would dissociate the latter from any form of effective control of individuals on the conditions of their existence, they must strive to state this language and boldly defend the idea that the mastery of inequality is a condition of independence, without leaving to others the usurped monopoly of claim to speak alone for the freedom of the individual while preserving the dubious privilege of pleading for greater equality which would only be a supplement, a means of exercising freedom and not of constituting it.

Is this reasoning as convincing as it sounds? Is it enough to justify the proposals for abandoning the welfare state and returning to the idiom of classical liberalism which, these are only examples, excludes any legal limitation of working hours and any legislation imposing a minimum wage? and demands that everyone only have access to medical care for which they are willing to bear the cost? Of course, no one thinks of denying the difficulties which "decent society" encountered after a prosperous period during which it appeared capable of jointly solving the problem of wealth creation and that of justice. 
But conversely, it is also necessary to take into account, without rejecting it as incoherent, the "classic" assertion according to which a company cannot claim to be legitimate if, ignoring all impartiality, the public power which represents it forces certain citizens to attend. others without asking whether the former have any responsibility for the disadvantaged situation of the latter? Isn't it violating the most basic rights - ownership of oneself and one's work - by doing so? Those who want to continue to speak this classic language are certainly not out of their common sense and their objections deserve to be taken seriously. There is therefore indeed an alternative political language that considers that the control of inequalities is the very condition of the existence of freedom because it requires that access to the means to make independent choices be distributed equitably and that no one may find himself at risk of losing control of his existence. But for the past thirty years, the repeated intellectual offensives waged against this alternative language of freedom in the name of a return to classical liberalism have been so effective that they have practically rendered it invisible and that the author finds it difficult to understand how much the redistributive state is neither an unhealthy outgrowth nor a luxury, but the very material of a society of free individuals. The protection of the weakest and the promotion of equality in access to the means of independence would constitute a heretical break with the formal impartiality of the rule of law. But if under the guise of equality before the law, the equal protection granted to unequal situations is itself a form of partiality which in another way engages the public power alongside the strongest, this argument loses all its validity. relevance. If we are talking about rents that proliferate under the rule of law, the state bureaucracy and the "insiders" who enjoy union protections are perhaps not the only groups concerned.

\section{Conclusion}

The protection society would contradict the responsibility that everyone must assume concerning the consequences of their own choices. Can anyone seriously claim that, in today's societies, everyone's situation is the personal consequence of their actions? On the contrary, it is increasingly true that wealth is a political work, that individuals are integrated into interdependent relationships, and that, far from being independent economic actors, they are integrated into more organizations. vast whose decisions escape them. This does not mean that the notions of responsibility and merit are devoid of meaning, but only that they cannot have political applications, both because they involve questionable metaphysical notions and because, in any event, the production of political legitimacy cannot be reduced to judging individuals and attempting to allocate to them a share of resources following their contribution. The proponents of classical liberalism are, moreover, the first to recognize that in a society founded on the impersonality of rules, there can be no guaranteed proportion between the efforts made and the results obtained. Most of the studies in the review tended to do a rigorous evaluation of one effect, with a less rigorous supplemental look at the other effects of interest (Khan, 2020c). The debate is not over, but it must continue. Today, however, its vitality is threatened by the inability of progressivism to clearly articulate the concept of individual freedom which justifies the aspiration for a more equal distribution - better guaranteeing the independence of all - of wealth. The proponents of this more substantial conception of freedom have, so to speak, allowed themselves to be drawn into the dilemma of freedom and equality. They surrendered to their adversaries the right to embody the liberty of the individual in the exclusive form of equality before the law, content to claim the task of moderating its demands in the name of a distinct value that would be greater equality or greater justice in access to the conditions of independence. But let's face it: equality in itself is not a value sui juris. It derives its normative force only from the independence to which it can alone confer a reality, that is to say from the fact that it is the condition of freedom. Why should a society of individuals promote equality? Because, apart from the pursuit of this objective, the functioning of an institutional framework composed of impartial laws and individual rights engenders dependence, terminates the means essential to the control of our existence in the hands of others. It is neither the effect of a class war nor that of any appetite for domination, but the inevitable consequence of a randomly unequal distribution of the initial advantages (talents, access to resources), the effects of which are cumulative and predictable. Here too it must be admitted frankly: the implementation of classical language - employing the granted protection of the right to property and the freedom of contract - does not necessarily lead to a society in which everyone can exercise control over his own life. Equal rights are not the sufficient basis for the freedom of all. By its very existence, the political state, therefore, undermined the classic idea according to which individual freedom consists in the absence of any legal privilege and in the fact of being subject only to 
impersonal laws outlawing political classes. Abstract actions which have the common characteristic of deliberately causing harm to others. In the new paradigm - never clearly articulated - it ceased to be true that one could only be deprived of part of one's property for a fault judicially established towards a third party. State officials acted as judges and imposed restrictions on human dignity, individual liberty and the freedom to contract by compelling citizens to make transfers that they did not consent to and by prohibiting certain private transactions because their effects - while not intentionally harming anyone conflicted with the satisfaction of everyone's needs. Finally, chance, even that which is due only to the difference in individual qualities, could no longer freely produce its effects, and organized solidarity forced them to collectively assume the impact.

\section{Acknowledgement}

The author acknowledges there was no external funding support; the author solely contributed accordingly in every part of the paper.

\section{References}

Ashcroft, R. E. (2005). Making sense of dignity. Journal of medical ethics, 31(11), 679-682.

Caulfield, T., \& Chapman, A. (2005). Human dignity as a criterion for science policy. PLoS Medicine, 2(8), $e 244$.

De Vos, A. S., Strydom, H., Fouche, C. B., \& Delport, C. S. L. (2005). Research at grass roots. Pretoria. Government Printers.

Esterhuyse, W. (2004). Recovering the soul of the South African nation. South Africa at, 10.

Freeman, M. (1994). The philosophical foundations of human rights. Hum. Rts. Q., 16, 491.

Habermas, J. (2006). Political communication in media society: Does democracy still enjoy an epistemic dimension? The impact of normative theory on empirical research. Communication theory, 16(4), 411-426.

Khan, M. M. R. (2020a). Strategic human resource management in facilitating the organizational performance: Birds-eye view from Bangladesh. Annals of Management and Organization Research, 2(1), 13-24.

Khan, M. M. R. (2020b). Covid-19's impact on Fresh Graduate's Job Market in Bangladesh: An observational study. Journal of Business and Management Studies, 2(1), 40-48.

Khan, M. M. R. (2020c). Rationalizing the Relationship between Ergonomics and Human Resource Management. Journal of Mechanical, Civil and Industrial Engineering, 1(1), 31-35.

Khan, M. M. R. (2021). Women and Sports: View from Stereotyping and Gender Differentials Perspectives. Journal of Sports and Physical Education Studies, 1(1), 01-04.

Macklin, R. (2003). Dignity is a useless concept.

Merrill, J. C. (2004). Global press philosophies. Global journalism: Topical issues and Media Systems, 3-18.

Nathan, S. M. (2003). International law.

O'Donovan, J. L. (2010). Human dignity and human justice in theological perspective. The grandeur of reason, 118-135.

Pipes, R. (1999). Life, Liberty, Property. Commentary, 107(3), 17.

Rawls, J. (1999). A Theory of Justice, rev. edn (1st edn 1971).

South Africa. President (1999-2008: Mbeki), \& Mbeki, T. (2004). State of the Nation address.

Vogel, B. (Ed.). (2007). At the centre: Human dignity: christian responsibility as a basis für the practice of politics: christian ethics as a guide. Konrad Adenauer Foundation 